\title{
Promising Application of Neodymium Oxide Nano Films in Microelectronics
}

\author{
Arun Chandra Sarmah \\ Department of Physics, Digboi College P.O. Digboi- 786171, Assam, India
}

\begin{abstract}
The AC conduction mechanism of vacuum deposited Neodymium Oxide $\left(\mathrm{Nd}_{2} \mathrm{O}_{3}\right)$ nano films with Aluminium top and counter electrodes were investigated at temperature range 302-528 $\mathrm{K}$ and within the thickness range 90-175 $\mathrm{nm}$. The variations of capacitance $(C)$ with frequency $(0.06-50 \mathrm{kHz})$ at different temperatures were also observed. It was found that the capacitance was frequency dependent at all temperatures but almost independent in the high frequency range beyond $1 \mathrm{kHz}$. From the variation of dielectric loss (tand) with frequency it was seen that tan $\delta$ values decrease rapidly with frequency and attains a minimum value. The variation of $C$ with $T$ at various frequencies was also studied and was found that $C$ almost remain constant almost upto $440 \mathrm{~K}$ and then increases sharply with temperature. At low frequencies $C$ increases sharply with temperature. From the tan $\delta$ versus $T$ characteristics at different frequencies it was observed that in the temperature range upto $460 \mathrm{~K}$. tan $\delta$ almost remained constant but increased sharply with $T$ at frequencies below $1 \mathrm{kHz}$ or below. A non-linear variation of $1 / \mathrm{C}^{2}$ with voltage did not indicate the presence of Schottky barriers. $\mathrm{Nd}_{2} \mathrm{O}_{3}$ nano films show low capacitance density $0.0021 \mu \mathrm{F} \mathrm{cm}{ }^{-2}$ and low dielectric loss 0.008 at $1 \mathrm{kHz}$ and at $300 \mathrm{~K}$. On account of stable properties, low dielectric loss and high dielectric constant the application of $\mathrm{Nd}_{2} \mathrm{O}_{3}$ nano films in electronic microcircuits will give promising result.
\end{abstract}

Keywords: AC conduction, activation energy, capacitance density, dielectric loss, dielectric constant

\section{Introduction}

With the development of integrated thin film circuits many investigations of the dielectric films have been made. Investigators have directed their attention to thin insulating nano films of rare earth oxides owing to their excellent mechanical, thermal and chemical stability. Many researchers [1-5] had carried out research work on different properties of Neodymium oxide $\left(\mathrm{Nd}_{2} \mathrm{O}_{3}\right)$ thin films at different conditions using different deposition techniques. In this paper we are going to present the ac properties of vacuum deposited $\mathrm{Nd}_{2} \mathrm{O}_{3}$ nano films of different thicknesses at different temperatures.

\section{Experimental}

\subsection{Film preparation}

The thin film Al| $\left|\mathrm{Nd}_{2} \mathrm{O}_{3}\right| \mathrm{Al}$ structures were fabricated in a series of vacuum deposition using suitable masks in each case at a pressure about $2 \times 10^{-5}$ Torr. Samarium oxide of purity $99.9 \%$ (Lieco Industries Inc, New York) were vacuum deposited over aluminium from tungsten basket at $393 \mathrm{~K}$ substrate temperature. The rate of deposition was varied from 0.062 to $0.133 \mathrm{~nm} \mathrm{~s}^{-1}$. The oxide films were then stored in dry air for 2-3 days and then counter electrodes were deposited to complete the $\mathrm{Al}-\mathrm{Nd}_{2} \mathrm{O}_{3}-\mathrm{Al}$ sandwiched structures. The films were then baked in air at about 373 to $473 \mathrm{~K}$ for 2-4 hours and then stored in dry air for a week to obtain stable properties. The sandwiched structures were then annealed at about $10^{-2}$ Torr pressure to a maximum of temperature $530 \mathrm{~K}$ in repeated heating and cooling cycles. The area of the oxide films were always much larger than the effective electrode area, so that the leakage current would be negligible. Prior to evaporation the oxide was degassed for 30 to 45 minutes under the shutter by heating the tungsten basket under low power conditions.

\subsection{Area and thickness measurements}

The film thickness' $d$ ' of $\mathrm{Nd}_{2} \mathrm{O}_{3}$ was determined capacitively at $1 \mathrm{kHz}$, taking the dielectric constant $\left(\mathrm{C}_{\mathrm{r}}\right)$ of $\mathrm{Nd}_{2} \mathrm{O}_{3}$ as 12.64 [ref. 5]. The effective area of the $\mathrm{Al}\left|\mathrm{Nd}_{2} \mathrm{O}_{3}\right| \mathrm{Al}$ structures were finally measured using a travelling microscope.

\subsection{AC measurements}

The capacitance $(\mathrm{C})$ and dielectric loss factor $(\tan \delta)$ were measured at different frequencies from 0.06 $50 \mathrm{kHz}$ and at different temperatures within 297 to $528 \mathrm{~K}$ and within the thickness range 90-175 $\mathrm{nm}$ using Marconi bridge (TF 2700). An external audio-frequency generator was employed to energize the bridge. Capacitance with the change of voltage at constant frequency was also measured. 


\section{Results} amorphous.

The vacuum deposited $\mathrm{Nd}_{2} \mathrm{O}_{3}$ when examined by the X-ray diffraction methods were found to be

\subsection{Effect of frequency}

The variation of $\mathrm{C}$ with $\mathrm{f}(0.06-50 \mathrm{kHz})$ at various temperatures $(302-528 \mathrm{~K})$ of thickness $115 \mathrm{~nm}$ is shown in Fig. 1. It is observed that the capacitance is frequency dependent at all temperatures but almost independent in the high frequency range beyond $1 \mathrm{kHz}$.

The variation of $\tan \delta$ with frequency is shown in Fig. 2. The $\tan \delta$ value decreases rapidly with $\mathrm{f}$ and attains a minimum value.

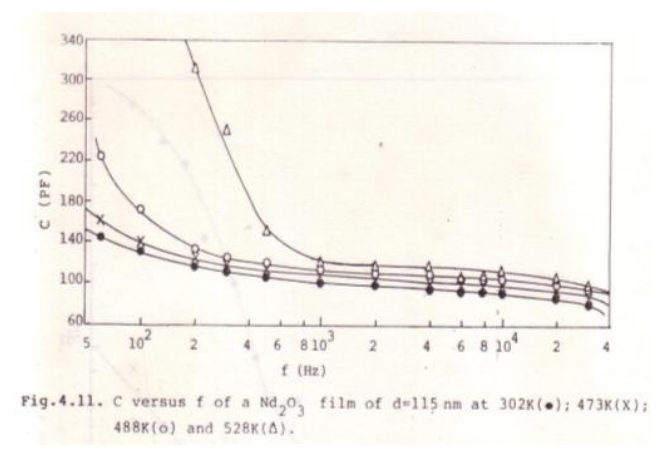

Fig. 1.

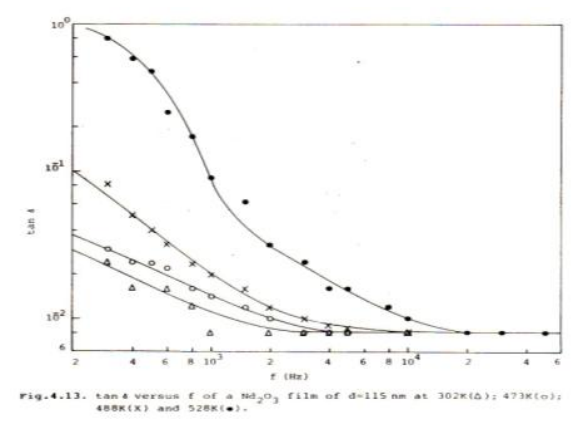

Fig. 2

\subsection{Effect of Temperature}

The variation of $\mathrm{C}$ with $\mathrm{T}$ at different frequencies within the temperature range 302 to $528 \mathrm{~K}$ is shown in Fig. 3. It is seen that the $\mathrm{C}$ decreases first with $\mathrm{T}$ and then almost remain constant upto $440 \mathrm{~K}$ and then increases with $\mathrm{T}$ at different frequencies. At low frequency $\mathrm{C}$ increases rapidly with $\mathrm{T}$. The variation of $\tan \delta$ with $\mathrm{T}$ at different frequencies is shown in Fig. 4. In the temperature range upto about $460 \mathrm{~K}$, $\tan \delta$ almost remain constant but it increases sharply with $\mathrm{T}$ at frequencies $1 \mathrm{kHz}$ or below.

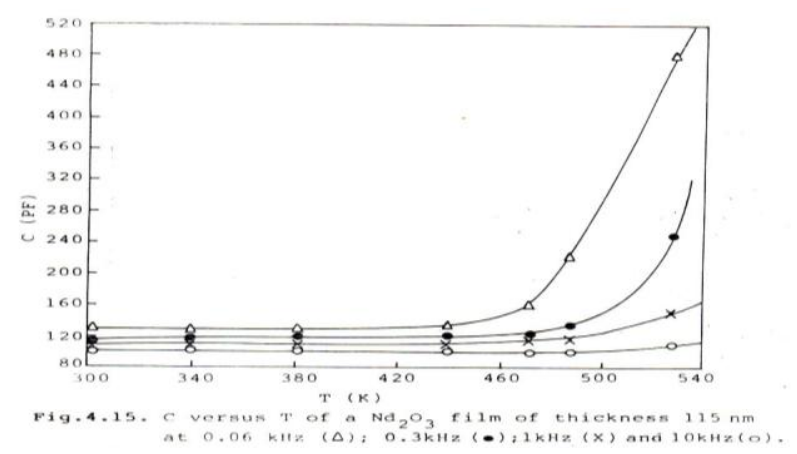

Fig. 3

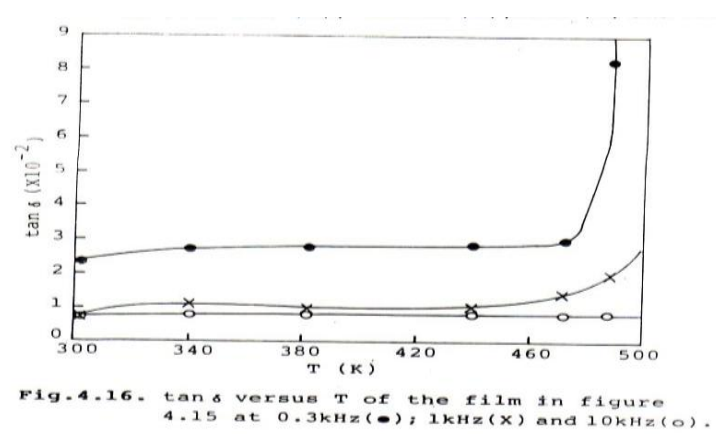

Fig. 4

The temperature co-efficient of capacity (TCC) was calculated using the relation

$\mathrm{TCC}=$

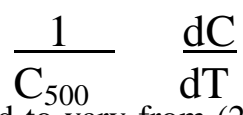

The value of TCC was found to vary from $(2.5$ to 3.25$) \times 10^{-2} \mathrm{~K}^{-1}$ for different film thicknesses at frequency 1 $\mathrm{kHz}$.

\subsection{Voltage effects}

A non-linear variation of $1 / \mathrm{C}^{2}$ with voltage applied between the two electrodes is observed.

\section{Discussions}

This study clearly indicates that the films prepared are amorphous in nature. The increase of both capacitance and $\tan \delta$ towards the low frequency and in the high temperature region could be attributed to the effect of interfacial polarization in that region. The charge carriers existing in the dielectric film can migrate for some distance under the influence of an applied field. When such carriers are blocked at the electrodes a spacecharge region results. This space-charge region leads to a substantial increase in capacitance towards low 
frequencies [7]. Similar observations for insulating films have been reported by earlier workers [8, 9]. The capacitance increases with temperature with a larger co-efficient could be due to the increase in film current caused by ionic motion with temperature.

The frequency dependence of $\tan \delta$ suggests that the losses are caused by a conduction process and in this case the value of $\tan \delta$ would decrease with the frequency according to a hyperbolical law $(\tan \delta=1 / \omega \mathrm{RC})$.

Fig. 5 show the plots of $\log \omega$ versus $1 / \mathrm{T}$ at three values of capacitance. The plots are linear and parallel. By equating the slope of $\log \omega$ versus $1 / T$ plot to $\phi / R$, the activation energy $(\phi)$ can be determined. The average $\phi$ values was found to be $0.73 \mathrm{eV}$. The large value of $\phi$ suggests that the conduction in the oxide films is ionic in nature and in this specific case the conduction could be due to the oxygen ion vacancies in the film structure.

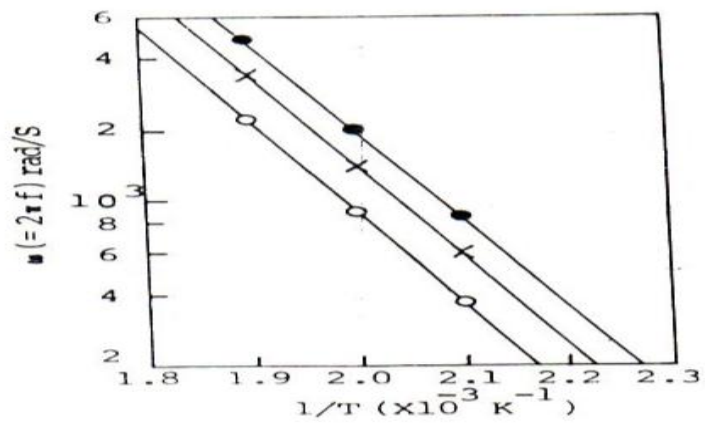

Fig. 5

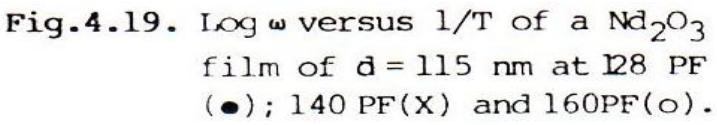

The variation of $\tan \delta$ with T reveals some structural defects or oxygen vacancies in the process of film formation [10]. The tan $\delta$ almost remain constant for temperature upto $440 \mathrm{~K}$ [Fig.4] and increases much more quickly above this temperature. This faster increase of $\tan \delta$ can be assigned to the space charge polarization of thermally generated charge carriers [6].

The non-linear characteristics obtained from the plot of $1 / \mathrm{C}^{2}$ versus $\mathrm{V}$ do not indicate the presence of schottky barriers in these composites [11].

The calculated values of resistivity $(\rho)$ at $300 \mathrm{~K}$ and at $1 \mathrm{kHz}$ was found to be $10^{7}$ to $10^{8}$ ohm-meter (using the relation $\tan \delta=1 / \omega \mathrm{RC}$ ).

\section{Conclusions}

The $\mathrm{Al}-\mathrm{Nd}_{2} \mathrm{O}_{3}-\mathrm{Al}$ MIM structures have been fabricated and characterized using $\mathrm{AC}$ conduction mechanism. Vacuum deposited $\mathrm{Nd}_{2} \mathrm{O}_{3}$ films were amorphous in nature. The average activation energy was found to be $0.73 \mathrm{eV}$. MIM capacitors show low capacitance densities $0.0021 \mu \mathrm{F} \mathrm{cm}^{-2}$ and low losses 0.008 at 1 $\mathrm{kHz}$ and at $300 \mathrm{~K}$. The TCC at $1 \mathrm{kHz}$ was found to be within $(2.5$ to 3.25$) \times 10^{-2} \mathrm{~K}^{-1}$ at $500 \mathrm{~K}$ for different film thicknesses. AC properties did not alter when stored in dry air for several months. On account of stable properties, low dielectric loss and capacitance densities high dielectric constant the applications of $\mathrm{Nd}_{2} \mathrm{O}_{3}$ nano films in electronic microcircuits will give a promising result.

\section{References}

[1] D. Bloor and J.R. Dean J. Phys. C, Solid State Phys, 5, 1972, 1237.

[2] P. Deshmukh, P. Deshmukh and M. Chintamani, J. Phys. C., 14, 1981, 531.

[3] M. Langlet and F.D. Shannon, Thin Solid Film, 186, 1990, L1-L5

[4] H.T. Fulham and F.P. Roberts, Proc. $8^{\text {th }}$ Rare Earth Res. Conf., TA Henrie and RE Lindotron (New York : Golden and Reach, VolI), 1970

[5] V.S. Dharmadhikari and A. Goswami, Thin Solid Films, 87, 1982, 119

[6] H.B. Lal J. Phys. C, 13, 1980, 3969

[7] A. Von Hippel, E.P. Gross, F.G. Telstia and A. Geller, Phys. Rev. 91, 1953, 568

[8] F. Argall and A.K. Joncher, Thin Solid Films, 2, 1968, 185

[9] H.J. Birey, J. Appl. Phys., 49, 1978, 2898

[10] T. Tsutsumi, Jpn. J. Appl. Phys., 9, 1970, 735

[11] B. Bhushan, S.C. Kashyap and K.L. Chopra, J. Appl. Phys. 52, 1981, 2932 